\author{
Ivana Ilić \\ University of Arts in Belgrade \\ Faculty of Music \\ Department of Music Theory
}

\title{
NOISE IN INNER SILENCE BY MILOŠ ZATKALIK: THE PLACE WHERE COMPOSITION, THEORY AND ANALYSIS BECOME ONE ${ }^{1}$
}

"An art aware of itself is an analysed art".2

(Theodor W. Adorno)

\begin{abstract}
In this text the composition Noise in Inner Silence by Miloš Zatkalik is discussed from the viewpoint of transformation which, influenced by the composer's theoretical work, took place in his creative output approximately during the last ten years. The

\footnotetext{
1 This research is a part of the science project of the Department of Musicology of the Faculty of Music in Belgrade The Identities of Serbian Music in the World Cultural Context (the number of the project 177019) financed by the Ministry of Education, Science and Technological Development of the Republic of Serbia.

2 Theodor W. Adorno, "On the Problem of Musical Analysis. Introduced and translated by Max Paddison”, Music Analysis, Vol. 1, 2, 1982, 176.
} 
creative process and the theoretical work are viewed as two equal, parallel and mutually permeated domains, and the relationship between their products as two-way: the writings are a metalanguage of the musical work, whereas the work itself reconsiders and complements, in a critical and a creative way, the theory that lies in its basis. The analytical emphasis is on large-scale goal-oriented processes in the musical flow.

Keywords: Miloš Zatkalik, goal-oriented processes, tonal center, referential sonority, music analysis

There are certain musical works which have the power to immediately seize the listeners' attention. These are the works that - by means of some forces, mechanisms and processes, whose impulses and modus operandi cannot entirely be realized and explained - make such a strong connection with our musical experience that they become a lifelong constituent of our cognitive and experiental world. Once they establish that connection, these works begin to communicate with us. Sometimes they do it unobtrusively, almost inaudibly, sometimes very loudly; sometimes because we call them ourselves, sometimes involuntarily and sometimes in such a way that we are not even aware of our inner dialogue with them.

Whatever the way may be in which these works continue their life within us and with us, they always 'want' just one thing from us: to return to them repeatedly. The beauty of mutual recognition of a musical work and its listener lies in the fact that the listener will want exactly the same thing. That is why we will conjure up in our memory the music which so intensively occupied us, we will evoke its sounds, colors, atmospheres, we will listen to the recording, we'll open the score, we will read the composer's comment about the work, we'll write a few words. And we will do all of that because we are intrigued by that music and encouraged to think about it, because we are dragged into exploring it in such dimensions and spheres, and from such perspectives and angles which at first we couldn't even have assumed to exist. As with true friends, who we always have something to share with even though we haven't seen or heard from each other for a long time, we can always say something about these works that has a specific meaning and is of specific importance to us in a certain spatial and temporal context.

And the same thing happens with this text. I return to the composition Noise in Inner Silence $e^{3}$ for oboe, clarinet, percussions and piano by Miloš Zatkalik not

3 The composition Noise in Inner Silence was written in 2014 and premiered on September $27^{\text {th }} 2015$ within the $24^{\text {th }}$ International Review of Composers by the Gradilište ensemble (Marina Nenadović, flute; Bojan Pešić, oboe; Veljko Klenkovski, clarinet; Ivan Marjanović, 
long after I wrote about it for the first time, because since the time I initially heard it until today it had a special meaning and importance for me in a professional as well as in - to a certain extent - a personal way. ${ }^{4}$ The professional aspect encompasses the professional and the creative challenge which contemporary music poses to the music writer. In the mutual encounter of the practically endless heterogeneous collection of composers' poetics, ways of musical thinking and compositional-technical procedures in music today on the one hand, and equally diverse scope of music-theoretical knowledge, experiences and sensibilities with which the listener approaches the work on the other, it is not hard to imagine a situation where the musical work and its listener pass by each other. But this was not the case here. I was especially intrigued by Zatkalik's work from the very first bar: the more I listened to it and analyzed it, the stronger my impression that I knew it from somewhere. Out of that at first quite vague impression, a personal dimension of my relation with that work gradually started to emerge, as well as the primary reason for my return to it on this occasion: I have been cooperating with Miloš Zatkalik on courses in Music Analysis for all of sixteen years. And during all of that time, I talked with him about music, theory and analysis many times, but not once have I written about his oeuvre, although there were occasions when I thought that maybe I could say a few things. ${ }^{5}$ During these years I have had the opportunity (and the privilege) to gain a close insight into the way in which Zatkalik observes music, musical work and the processes which direct its flow, the way he notices and resolves analytically provocative situations, poses analytical problems and explains them theoretically. While I was listening to the composition Noise in Inner Silence and analyzing it, I had the impression that I was having one such conversation with the composer or that I was read-

percussion; Neda Hofman, piano). The sound example is available online at the official New Sound YouTube channel. Please find the playlist here: https://youtu.be/tnzXCtXfByE

4 My first encounter with the composition Noise in Inner Silence by Miloš Zatkalik took place when the author invited me to talk about it at the review New Sound Spaces of the Center for Music Action which was held on March $30^{\text {th }}$ 2018. In accordance with the occasion and the time given for the presentation, I took a global look upon the whole of Zatkalik's composition, pointed out the major musical processes that guide it and marked the themes which it opens. The text I read is available on the web page www.cma.org.rs. Although it was inevitable to repeat in this paper the basic information about the work, its formation and structure, as well as certain observations and conclusions I presented at the mentioned review, the text that follows represents - by its conception, focus and the nature of the analytical and theoretical argumentation - a completely new contribution to the reception of Zatkalik's piece.

5 One of the occasions was the premiere of Zatkalik's composition Lost Fragments 2 for clarinet, cello and piano within the $16^{\text {th }}$ International Review of Composers $\left(23^{\text {rd }}-27^{\text {th }}\right.$ November 2007). 
ing one of his texts. In other words, as if there was no difference between the thing I had till then known as Zatkalik's thinking about music and the thing that I - while listening to this work again and again - got to know as his thinking in music, but that the creative process and the theoretical work so closely pervaded each other that they became one, so that it wasn't possible to distinguish where the creative process ended and where the theory began, and vice versa. ${ }^{6} \mathrm{My}$ intention in this paper is to shed light on the described unity of thinking about and in music in the composition Noise in Inner Silence.

The fact that this can be a fruitful perspective for access not only to this work, but also to Zatkalik's other works composed in the past ten years, was pointed out by the composer himself. In the quote below, the composer indicates, beside the key to understanding his works that date from the period mentioned above, the substantial features of the transformation - considering compositional technique, musical language and musical expression in general - that took place within his oeuvre under the influence of his theoretical work.

It is irrefutable [...] that my research over the last six or seven years, much deeper analytical engagement with works of more recent music [...], my new awareness of the analytical naiveté with which I used to approach works of such major 20th-century personalities like Webern, Varese, Ligeti: all this made me see my own music in a new light. Not through direct influence, of course, but in a hardly explicable way, as my theoretical analytical activities unfolded, I became aware that what suited me was rather different from what I had previously done. I ought not to be allowed to write longer pieces. Or, huge gradation ending in dramatic climaxes I used to revel in such situations, while my attempts to do something of the kind turned out to be quite lame. And then, there was my obsession with forcing into the composition some semi-clandestine signals which purported to contribute to its coherence and integration. I've been much more satisfied since I stopped thinking about that. Let's call it the awakening from a "dogmatic slumber". 7

Although the interview that contains this quotation was made two years before Zatkalik wrote Noise in Inner Silence, the things the composer said at the time could be applied to the composition in question. Beside the embodiment of an important constant value in Zatkalik's creative otuput, the one that concerns the correlation of musical creation and imagination on the one hand and non-mu-

6 Thinking about music, especially when it includes music analysis, can also under certain circumstances be understood as thinking in music, but that discussion would lead me very far from my primary goal in this text. The distinction which I made primarily has an operative meaning: to indicate that I talk about the mutuality of the two domains (the theoretical and the creative one) and two corresponding ways of expression (the verbal and the musical one).

7 Milena Medić, "Music is not a Language", Interview with Miloš Zatkalik, New Sound, 42, II/2013, 13-14. 
sical impulses, above all literary, but also visual ones on the other - Noise... is a particular 'music transposition' of one of the subjects that Zatkalik's theoretical work has been connected with during the last ten years: the goal-oriented long-term musical processes in non-tonal music. ${ }^{8}$ This composition represents the creative response of Zatkalik the composer to the question of Zatkalik the theorist "whether the non-tonal composer is capable of projecting meaningful expectations and goals, of setting up a process which would unfold over a larger time-span?" The dramaturgical and formal characteristics of the work derive from the affirmative musical answer to this question. Thus, in Noise in Inner Silence there are no 'huge gradations ending in dramatic climaxes', but some gradations ending in some climaxes - even if these gradations are not 'small' or 'huge' and these climaxes are not dramatic in the sense which the author, I suppose, must have had in mind - undoubtedly exist. Also, in Noise... there really is no 'obsession with forcing' the elements that should integrate six movements of the piece into a cycle, but some other factors of integration - realized in a much more subtle way - exist despite the composer's claim that there was no "conscious effort to achieve 'organic unity' and wholeness". ${ }^{10}$

In light of Zatkalik's music-theoretical work, I will further on discuss the ways in which goal-oriented musical processes are realized in the composition Noise in Inner Silence. Zatkalik's major texts concerning this problem were written so to speak in parallel with the composition itself. ${ }^{11}$ Therefore, there is a two-way relation between the music-theoretical and the musical discourse: Zatkalik's writings are a metalanguage of Zatkalik's work, but the work itself also

8 The composer himself pointed out the non-musical referential layer of this work by giving a title to each movement. The titles of the movements are: "Scream", after the painting by Edvard Munch, "Cries and Whispers" after Ingmar Bergman's movie with the same title (Viskningar och rop), "As if the Mist Itself Had Screamed", the sentence from Joseph Conrad's novel Heart of Darkness, "The Voice of the One Crying in the Desert" as the fragment of the Gospel of John, "The Sound and the Fury", after the same titled novel by William Faulkner, who borrowed from Shakespeare's Macbeth, and "The Rest is Silence", which is the last line of Hamlet in William Shakespeare's piece. In the written comment about the work, Zatkalik points out that he cannot say "that these ingenious creators were the inspiration for this composition", but that the piece - once it was finished - "invoked them in a way".

9 Miloš Zatkalik, "The Aggregate or Have the Notes Lost Orientation?", Musicological Annual, Vol. XLIV, 2, 2008, 73-74.

10 The quote comes from the author's comment that was available to me in the electronic format.

11 Cf. "The Aggregate...", op. cit., 69-86; "Reconsidering Teleological Aspects of Non-Tonal Music", in: Denis Collins (Ed.), Music Theory and Its Methods: Structures, Challenges, Directions, Frankfurt am Main: Peter Lang Publishers, 2013, 265-300; "Teleological Strategies of Nontonal Music: The Case of Milan Mihajlović”, New Sound, 45, I/2015, 119-138. 
reconsiders and complements, in a critical and a creative way, the theory that lies in its basis. The indicated two-way relation does not, in any sense, mean the reconstruction of the chronology and the course of mutual influences between music theory and analysis on the one hand and the composer's work on the other, but the selective - innate to the musical work's organization itself - application of theoretical concepts discussed in the composer's writings and analytical strategies that derive from them. ${ }^{12}$ Therefore, any methodological resonance between this and Zatkalik's writings is conscious and deliberate.

Let us begin with the global conception of the composition Noise in Inner Silence. (Table1) In the overall structure of six movements, the first movement has the function of an introduction to the second movement, as well as the third movement to the fourth, which means that the two pairs of movements stand in the relation of translational symmetry to each other. The fifth movement reverses that relation as in a mirror, introducing the reflection symmetry in the whole process. The biting three-tone verticals that open the piece do not appear as it could be expected according to the established pattern (before the fifth movement, as a starting point in the third phase of one and the same process), but instead they are placed at the end of the next-to-last movement, as the goal of the music motion. The fifth movement is the only one in the cycle that doesn't begin attacca, which increases the change it enacts. The violent, furious, quasi-mechanistic triplet ostinato which this movement begins with, entirely changes the direction of the perception: the merging of the tempo (now twice faster than in the previous movements) with the insistently pulsating triplet ostinato in its first and last sections, and the imitative texture in the middle one, give the impression that time passes faster in the penultimate movement. Since the first, the third and the very end of the fifth movement (bb. 85-90) are mutually equivalent, as well as the second, the fourth and the fifth one, the transposition of the first and the second movement relation is realized along with the intensification of energy within the musical flow, so that each succeeding element in the chain of equivalences appears on a higher level than the previous one. Thus, a particular spiral dramaturgic curve of the piece reaches its climax in the fifth movement, the fourth movement has the function of an anticlimax, while the last one gains the meaning of an epilogue.

12 Zatkalik's theoretical assumptions and analytical strategies are built and formulated on the basis of his synthetic-interpretative-critical relationship towards the complex history and theory of the specified problems, which he extensively wrote about in many occasions. That circumstance determined my decision not to discuss the mentioned complexity of the theoretical platform I applied to the analysis of the piece. 
Ilić, Ivana: Noise in Inner Silence by Miloš Zatkalik: The Place Where Composition...

Table 1: Miloš Zatkalik, Noise in Inner Silence - The overall conception of the cycle

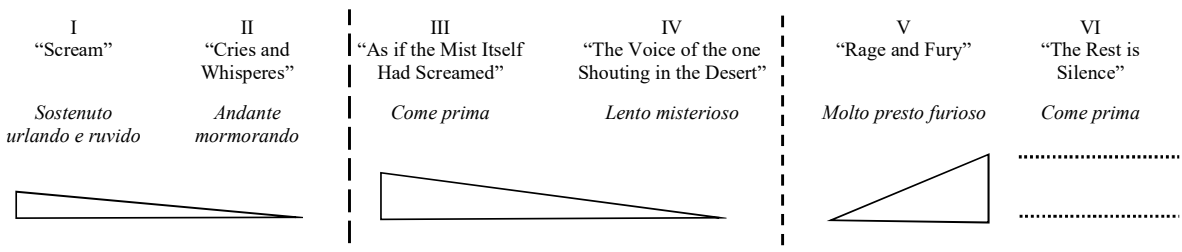

the axis of translational symmetry the axis of reflection symmetry

The overall framework depicted above is based on two fundamental strategies that, according to Zatkalik, allow the non-tonal music to move to a certain goal. The first one implies the establishment of a referential sonority, a kind of a particular 'tonic' of the composition, i.e. contextually understood consonance in relation to which the hierarchical relations of stability and instability are established, tracing, further on, the musical motion: the departure from the 'tonic' and the return to it. ${ }^{13}$ The other strategy includes the exhaustion of a given set of musical entities in a process which Zatkalik defines as the 'completion model'. ${ }^{14}$ It is based on a strategy which distinguishes a musical event or a set of relationships between musical events ("musical entity") within the musical flow and establishes it as the element of an integral set (a "family of entities"), afterwards the occurrence of these elements over the course of a given composition or a portion thereof is traced (the "unfolding of the family of entities") until the unfolding is complete, i.e. until all the entities have occurred. If that unfolding is realized in such a way that the exhaustion of all the elements of the set is recognized as having a special role in establishing a sense of arrival or closure of the musical flow (the "goal-defining family of entities"), then the very moment of the exhaustion of musical entities ("completion") gets a structural significance syntactic or a large-scale formal one. ${ }^{15}$

The musical events that can be recognized as the strategically designed goals of the musical motion Zatkalik defines in three points: 1) a point of arrival (e.g., a tonic, a given pitch or pitch collection), (2) a segment, broader entity: music can be aimed towards a theme, and especially towards the return of a previously stated (and subsequently fragmented) theme and (3) more abstractly, the

13 Cf. Miloš Zatkalik: “Teleological Strategies...,", op. cit.

14 Miloš Zatkalik, "Reconsidering Teleological Aspects...", op. cit., 287.

15 Zatkalik establishes the difference between the syntactic and the large-scale formal to draw the attention to the fact that the processes of completion in the musical flow can have more than pure local meaning. Cf. Miloš Zatkalik, "The Aggregate...”, op. cit., 76. 
goal can be the establishing of a certain "state of affairs," a set of relationships, e.g., establishing symmetry between musical entities, restoring the lost balance, resolving any issues raised by the previous flow of music, etc. ${ }^{16}$

The mechanisms of projecting and the realization of the large-scale processes in the composition Noise in Inner Silence are based on a particular use of two groups of elements and their mutual relationships: three distinctive scales and the implicit pitch centers. The pitch basis of this work consists of an octatonic scale, a whole tone scale and a chromatic one. In fact, any pitch constellation in the musical flow could be understood as a subset and sometimes as an equivalent of the one of the three scales, or as some kind of their pervasion, mutual overlap or a gradual outgrowth from one to another.

The exposition of their 'setting' and mutual relationships is placed in the first movement. There are three distinctive sets which are of crucial importance for the musical flow, whereby each one of them represents a subset of the one of the three aforementioned scales. All three sets are based on a strong vertical aspect which will also be of major importance for the further musical flow.

The initial three-tone vertical - a musical transposition of a scream, as it is indicated in the first movement's title - is presented in the flute, oboe and clarinet parts. It consists of a minor third and a major third $\left(\mathrm{C}^{3}-\mathrm{D}\right.$-sharp ${ }^{3}-$ $\left.\mathrm{E}^{3}[014]\right) .{ }^{17}$ The simultaneous sounding of two kinds of thirds unambiguously indicates the presence of an octatonic scale which initially appears here in its less common, vertical form. ${ }^{18}$ Although the distinctive sounding of the octatonic scale is lost when it is transferred from the linear to the vertical dimension, the three-tone verticals are highly individualized: they encompass a very narrow interval range, they sound in high register (in the highest octave of the register range of each instrument) and are then treated as pure sound mass, within the possibilities of the performing medium itself. The fact that the tone $\mathrm{C}$ is the fundamental tone of the first sonority can be significant for the further flow of the work, as will soon be pointed out.

The whole tone scale subset appears for the first time at the end of the first movement as the first syntactically relevant 'local' goal of the musical flow and as a result of a gradual transformation of the initial three-tone vertical. The

\footnotetext{
16 Cf. Miloš Zatkalik, “Reconsidering Teleological Aspects...”, op. cit., 269.

17 Two remarks are needed here: (1) the enharmonic equivalence is understood; (2) in naming the notes I use a variant of the Helmholtz pitch notation system (with digits indicating the number of primes).

18 The primarily melodic aspect of the octatonic scale's use in music is discussed by Dejan Despić in: Dejan Despić, Harmonija sa harmonskom analizom III, Beograd, Udruženje kompozitora Srbije i Savez udruženja kompozitora Jugoslavije, 1994, 80.
} 
transformational process unfolds in three steps which are based on a summarizing structure $n+n+2 n$ : the five-bar exposition of the material (bb. 1-5), its fourbar repetition (bb. 6-9) and a six-bar development with the closure signal (bb. 10-15), which all - bizarre as even the slightest thought about tonal references may sound in this context - has the effect of the opening movement acquiring the status of a stable and integral entity formally very close to the musical sentence of the developmental type. ${ }^{19}$ The "point of arrival" is represented by a new organization of the vertical in the woodwinds. It is the sonority $\mathrm{A}^{2}-\mathrm{C}$-sharp ${ }^{3}$ - E-flat ${ }^{3}[026]$ (b.13), the subset of the whole tone scale second transposition $\left(\mathrm{WS}_{2}\right) .{ }^{20}$ The final three-tone sonority $\left(\mathrm{G}^{2}-\mathrm{A}^{2}-\mathrm{C}\right.$-sharp $\left.{ }^{3} / \mathrm{bb} .14-15 /\right)$, covers the same narrow interval range and is based on the identical set as the previous one [026].

Two scales aren't entirely different from each other for they share four tones, while the remaining four tones of the octatonic scale have a kind of a leading tone relation toward the corresponding four tones of the whole tone scale. Nevertheless, the whole tone scale symbolizes a particular 'dissonance at a distance' which will 'resolve' in the penultimate movement. The $G$ that stands for the fundamental tone of the last three-tone vertical of the first movement can be related with the $\mathrm{C}$, which was the fundamental tone of the opening vertical. The importance of that $\mathrm{G}$ is underlined by the way it was reached in the clarinet part. The clarinet part is individualized by means of its gradual descending motion from E-flat ${ }^{3}$ to $\mathrm{G}^{2}$ (bb. 10-14), its rhythmic profile (the appearance of triplet half-notes and the lack of syncopation of the shorter note with the longer one)

Table 2: Miloš Zatkalik, Noise in Inner Silence - Structural scheme

\begin{tabular}{|c|c|c|c|c|c|c|c|c|c|c|c|c|c|c|c|c|}
\hline $\begin{array}{c}\mathrm{I} \\
\text { Sostenuto }\end{array}$ & \multicolumn{3}{|c|}{$\begin{array}{r}\mathrm{II} \\
\text { Andante mo }\end{array}$} & rmor & ando & \multicolumn{3}{|c|}{$\begin{array}{c}\text { III } \\
\text { Come prima }\end{array}$} & \multicolumn{3}{|c|}{$\begin{array}{c}\mathrm{IV} \\
\text { Lento misterioso }\end{array}$} & \multicolumn{4}{|c|}{$\begin{array}{c}\mathrm{V} \\
\text { Molto presto furioso }\end{array}$} & \multirow{2}{*}{$\begin{array}{c}\text { VI } \\
\text { Come prima } \\
\text { fragmentary } \\
\text { structure }\end{array}$} \\
\hline \multirow[t]{3}{*}{$\begin{array}{l}\text { 'sentence-like' } \\
\text { structure }\end{array}$} & $\mathrm{a}$ & b & $a_{1}$ & $\mathrm{~b}_{1}$ & Coda & a & $\mathrm{b}$ & & $\mathrm{a}$ & $\mathrm{b}$ & Coda & a & B & & $a_{1}$ & \\
\hline & 1 & 19 & 24 & 26 & 45 & 1 & 6 & & 1 & 22 & 40 & 1 & 22 & & 67 & \\
\hline & & & & & & & & & & & & $\begin{array}{c}\text { I } \\
22\end{array}$ & $\begin{array}{l}\text { II } \\
38\end{array}$ & $\begin{array}{l}\text { III } \\
55\end{array}$ & & \\
\hline $\begin{array}{l}\mathrm{OS}_{1,2,3,}, \mathrm{WS}_{2} \\
\quad+\mathrm{CS}\end{array}$ & & $\mathrm{WS}_{2}$ & , $\mathrm{WS}_{\mathrm{I}}$ & & $\mathrm{WS}_{2}$ & $\mathrm{OS}_{3,2}$ & $\begin{array}{l}\mathrm{WS}_{1} \\
+\mathrm{CS}\end{array}$ & $\mathrm{OS}_{1}$ & $\begin{array}{l}\mathrm{WS}_{1}, \mathrm{CS} \\
+\mathrm{WS}_{2}--\end{array}$ & $\begin{array}{l}\mathrm{WS}_{1} \\
+\mathrm{OS}_{1}\end{array}$ & $\mathrm{WS}_{2}, \mathrm{OS}_{1}$ & & $\mathrm{WS}_{1}$, & & & $\mathrm{OS}_{1}, \mathrm{CS}$ \\
\hline (G?) & & & & & & & & & G & A & $\mathrm{C} / \mathrm{A}$ & & & & $\mathrm{C}$ & $\mathrm{C}, \mathrm{A}$ \\
\hline
\end{tabular}

19 The formal schemes are given in Table 2.

20 I use the abbreviations $\mathrm{WS}_{1}$ and $\mathrm{WS}_{2}$ to designate two possible transpositions of the whole tone scale (from $\mathrm{C}$ and $\mathrm{C}$-sharp). 
and the range it encompasses (minor sixth in contrast to the narrow ranges of the remaining instrumental parts). ${ }^{21}$

The chromatic scale subset is represented with pairs of dyads in the piano part. That vertical is based on the simultaneous sounding of either major seventh and minor ninth or two minor ninths, whereby the primary forms of the tetrads thus obtained are identical [0123]. In contrast to the 'dense' set of the 'wind' verticals, the piano dyads' real pitches cover the range of more than two octaves, thus giving the acoustic frame to the three-tone verticals. The difference between a vertical which is treated as a sound mass (based on a narrow range, in high register) and a vertical treated as an autonomous chord (widely spaced) represents one of the constituents of the goal-oriented processes in this composition. The textural differentiation between the melodic and harmonic layers, which was already profiled in the mutual relationship between the woodwinds and the piano part, will have the same function.

The pairs of dyads in the piano part follow each of the three steps in the three-tone verticals' transformation process: their occurrence in a written accelerando (the number of the bars between the successive piano appearances is progressively reduced), the activation of the register at the very end of the closing sonority in the woodwinds (the dyads being transposed three octaves downwards) and the change of articulation (molto secco, $f$ sempre, without the right pedal in contrast to the pedalized sforzzato accents) speak in favor of that. Thus, the pairs of dyads in the piano part operate in joint action with the three-tone verticals, and they are also to a certain extent mutually separated, not being submitted to the transformation of their content (considering primary forms). The fact that the chromatic scale represents the superset of both the previous scales can be of certain significance for further interpretation.

The aforementioned three scales provide a solid system of pitch organization, but since each of them is symmetrical, none of them implies the inner hierarchy that would enable the establishment of the patterns of tension and release regarding the tonal center given in advance. In spite of that, the composition Noise in Inner Silence is not entirely deprived of pitch centering, albeit being a bit puzzling in this respect. Considering the fact that the first three-tone vertical appears in the original register and pitch content only once more throughout the composition - as the goal of the climax process in the fifth movement - one can conclude that despite the typical mass-like treatment of the three-tone verticals in the woodwinds, the $\mathrm{C}$ confirms itself as the principal pitch center of the work.

21 Here I don't have in mind the hierarchy between the tonic and the dominant, as it exists in the major-minor tonal system. I indicate the possibility that the prominent role that the tone $\mathrm{G}$ will have in the later processes is already implied in the first movement. 
Hence, the vertical $\mathrm{C}^{3}-\mathrm{D}$-sharp ${ }^{3}-\mathrm{E}^{3}[014]$ acquires the function of the referential sonority. (Example 1a)

Example 1: Miloš Zatkalik: Noise in inner silence - referential sonority and its transformations

a) $1^{\text {st }}$ movement, bb. $1-4$

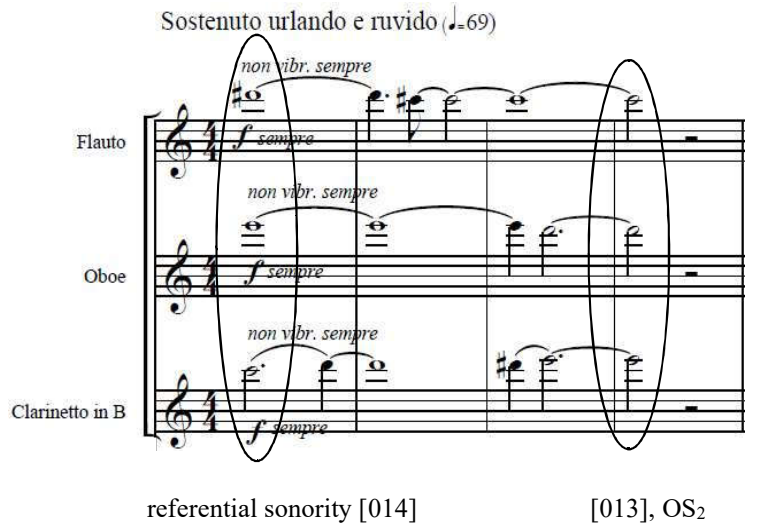
b) $1^{\text {st }}$ movement, b. 10
c) $3^{\text {rd }}$ movement, b. 1
d) $5^{\text {th }}$ movement, b. 16

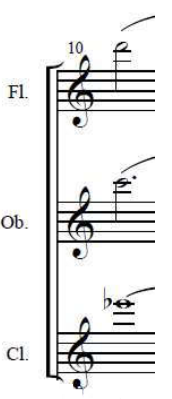

[013], $\mathrm{OS}_{3}$

Come prima $(\cdot=69)$

F1

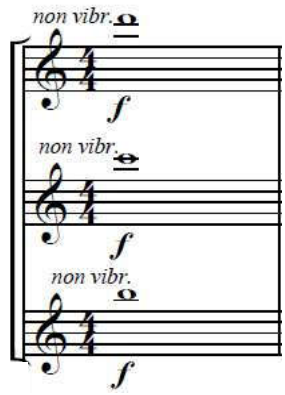

[013], $\mathrm{OS}_{3}$

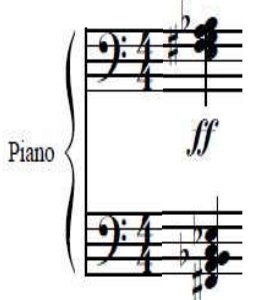

[0134679], OS 1

However, this work ends neither with the referential sonority nor with the $\mathrm{C}$, but with the tone cluster ${ }_{2} \mathrm{~A}-{ }_{1} \mathrm{E}$. Therefore, that vertical - even though it is produced by hitting the wire with the hand (bb. 45-50) - also represents the goal of a certain musical motion. The fact that the tone cluster ${ }_{2} \mathrm{~A}-{ }_{1} \mathrm{E}$ has already appeared in the same form and was performed in the same way during the fifth 
movement (bb. 14-15), as well as at the very beginning of the fourth movement coda (b. 40), speaks in favor of understanding its large-scale significance. It will be possible to say more about this when we consider all the major lines of the musical motion. At this point it is important to indicate that the tone cluster ${ }_{2} \mathrm{~A}$ $-{ }_{1} \mathrm{E}$ is not of lesser importance for the flow of music than the initial three-tone vertical, but 'only' different from it because of its chromatic structure, the specific request for its performance and noticeably quiet dynamics.

If $\mathrm{C}$ is the principal pitch center and the three-tone vertical $\mathrm{C}^{3}-\mathrm{D}$-sharp ${ }^{3}$ $-\mathrm{E}^{3}$ is the referential sonority, than the basic scale series of the composition is C - D-flat - E-flat - E - F-sharp - G - A - B-flat - C. ${ }^{22}$ The departures from it - in other words the differentiation between the more or less stable and unstable sonorities in a given frame - are realized in a joint action of three elements: its similarity with the other pitch structures, the interval of the transposition of the given sonorities and the transposition of the scale itself.

Two sonorities are especially important in this respect because they embody the nearest and the furthest position in the given context in relation to the referential sonority, whereby they also have a structural meaning. The first one, based on the set [013], creates the similarity relation with the referential sonority on two levels: the pitch-class $\left(\mathrm{R}_{\mathrm{p}}\right)$ and the interval class $\left(\mathrm{R}_{2}\right)$. The relationship $\mathrm{R}_{1}$ is established as well, which means that these two sets connects a high level of coherence. That is why it will be possible to replace at certain points the referential sonority with the set [013], for the set [013] - being a derived and thus a secondary sonority - will also signify a certain departure from the referential sonority, especially when its real pitch content represents a subset of one of the two other possible octatonic scale transpositions.

Thus, the departure from the referential sonority in the process of transformation of the initial three-tone vertical in the first movement is noticeable because the set [013] is first taken from the second and then from the third transposition of the octatonic scale. (Example 1a and 1b) From that moment on there is no possibility to return and the verticals are led to the new whole tone structure. The appearance of that set as the subset $\mathrm{OS}_{3}$ and its transposition to $\mathrm{B}$ at the very beginning of the third movement (Example 1c) indicates that the point of departure of this movement is represented by a higher level of tension in relation to the first movement.

In the third movement, a certain reinterpretation of the relations which crucially contributed to the phrase stability of the first movement takes place. The outgrowth of the sonorities based on the octatonic scale into the ones based on a whole tone scale is no more gradual, but it emphasizes the contrast between

22 In the following text I will label it with abbreviation $\mathrm{OS}_{1}$, and its other two possible transpositions with the abbreviations $\mathrm{OS}_{2}$ and $\mathrm{OS}_{3}$. 
these two structures of the musical flow's vertical dimension. The contrast is also underlined by the change of articulation (molto vibrato instead of non vibrato). A particular 'disassembly' of the starting and the closing point of the first movement and their juxtaposition result in a binary form of the third movement.

When the set [014] appears at the end of the third movement in such a way that the register range of the vertical in the woodwinds is expanded in its real sounding so that it spans almost three octaves $\left(E-C\right.$-sharp $\left.{ }^{2}-C^{3}\right)$ instead of the narrow spacing of pitches in one register, it becomes obvious that the departure from the referential sonority is significant, despite the fact that it represents $\mathrm{OS}_{1}$. For that change initiates the change of this sonority's status: from the vertical within the sound mass to the 'real' chord in its second inversion. This change by no means comes as a surprise, but it furthermore materializes a 'micro goal' of the musical motion: it stands for the space equivalent of the written temporal ritardando in the piano part (a progressive reduction of the note values) followed by a subtle space accelerando (a progressive segmentation of the figure).

The furthest point in relation to the referential sonority is represented by the set [0134679] which includes seven out of eight tones of the $\mathrm{OS}_{1}$ : it misses the D-flat. ${ }^{23}$ (Example 1d) Its fundamental tone is F-sharp, in polar relation to C, which cannot be ignored in spite of the symmetrical structure of the scale. For that tritone is the furthest from $\mathrm{C}$ : it divides the octave into two equal halves and cannot be reduced to any smaller interval, as it is possible to do with the interval inversions that are wider than the tritone. It appears for the first time in that form in b. 16, as a constituent of the local climax in the first section of the fifth movement (Molto presto furioso), then it sounds in some crucial moments of the three-stage development in the middle part, as well as at the very beginning (b. 67) and at the very end (bb. 77-79) of the intensified recapitulation, where it is transposed an octave downwards.

There are also less unstable appearances of this sonority. They are based on chords built of less than seven pitches. These sonorities are widespread throughout the whole fifth movement (from b. 7 onward). The fundamental tone F-sharp appears from the first bar of the next-to-last movement, as the lowest tone of the triplet ostinato based on the $\mathrm{WS}_{1}$. The involvement of the whole tone scale in the formation of that chord is not accidental. It is related to the mutual similarity of the two scales, as well as to the previously indicated 'dissonance at a distance' which in the first movement is symbolized by the subset of the whole tone scale [026].

23 In b. 8 of the fifth movement there is a chord that contains all eight tones of the octatonic scale, but being given as an echo of a sudden interruption of the previous ostinato, it has, above all, a coloristic and not a structural function. 
The return of the referential sonority does not represent the same level of stability which was characteristic of the beginning of the piece because there is another multilayered process crucial for the global conception of the work. It operates through the aforementioned overall establishment of the stable-unstable-stable relationships. Not all layers it includes come to an end in the fifth movement. The above mentioned process concerns the exhaustion of the pitch fund of the three scales structures and their transition from a predominantly vertical dimension to a horizontal one. Consequently, there is a musical entity based on one pitch class which becomes the constituent of the three mutually related families of entities (the first transposition of the octatonic scale with a finalis on $\mathrm{C}$, the chromatic scale and the two transpositions of the whole tone scale) on the one hand, and a musical entity based on a type of texture that becomes a part of a two-member constellation of a vertical and a horizontal dimension of the musical flow, on the other.

The layers of the mentioned process run one after another, mutually interweave and entangle in a specific way in the area around the golden section of the composition - on the border between the $a$ and $b$ sections of the fourth movement (b. 21). ${ }^{24}$ Two goal-defining families of entities exhaust themselves in the melodic layer of the musical flow at that point: two transpositions of the whole tone scale and the chromatic scale. These two events intersect, thus becoming estranged: the exhaustion of the $\mathrm{WS}_{2}$ occurs in the chromatically based musical flow, while the completion of the chromatic scale is used as an impulse for the tonal centering of the whole tone basis of the fourth movement's $b$ section.

The transition of the whole tone scale to the horizontal dimension and the exhaustion of the pitch class fund of its two transpositions begins in the second movement. The vibrating, Ligeti's micro polyphonic weaving lookalike, indifferente base in the woodwind parts in the $a$ and the $a_{1}$ sections, as well as the piano part's chordal accompaniment in the $b$ and the $b_{1}$ sections, is entirely based on $\mathrm{WS}_{2}$. Individual pitches or groups of pitches start to be clearly distinguished from the initial three-part texture by their register, articulation and dynamics, thus obtaining their melodic meaning. They encompass the pitch fund of the $\mathrm{WS}_{2}$, but that fund is not completely used in the second movement's melodic layer: it misses the pitch $\mathrm{G}$.

At the same time, in the same section, the 'conquering' of the $\mathrm{WS}_{1}$ fund in the oboe part (E and D, bb. 8-9) starts. That process will be finished at a distance, in the $b\left(\mathrm{C} / \mathrm{b} .20 /\right.$, A-flat /b.30/) and $b_{1}$ (B-flat/b. 39/ and G-flat/b. 41/) sections. The main feature of this process is a gradual withdrawal of the components of the oboe's original harmony with the other two wind parts. (Example 2) The

24 The golden section of the fourth movement itself is also placed in that bar. 
oboe part is singled out from its surroundings first by its register (in the $b$ section it carries the highest pitch $/ \mathrm{C}^{3} /$ ), then metrically (it is given in counter-rhythm in relation to the flute and the clarinet /bb. 20-22 and 27-34/) and finally it is motivically reduced to the literal or slightly varied repetition of melodic fragments which turn out to be somewhat 'powerless' and indifferent compared to the highly developed flute and clarinet two-part counterpoint /from b. 32 and especially b. 35/). Therefore, the oboe part does not participate in the motivic development and the liquidation of the material which result in the climax of the second movement, being withal the first climax in the cycle (bb. 42-43).

Example 2: Miloš Zatkalik, Noise in Inner Silence, 2nd movement, bb. 25-36.
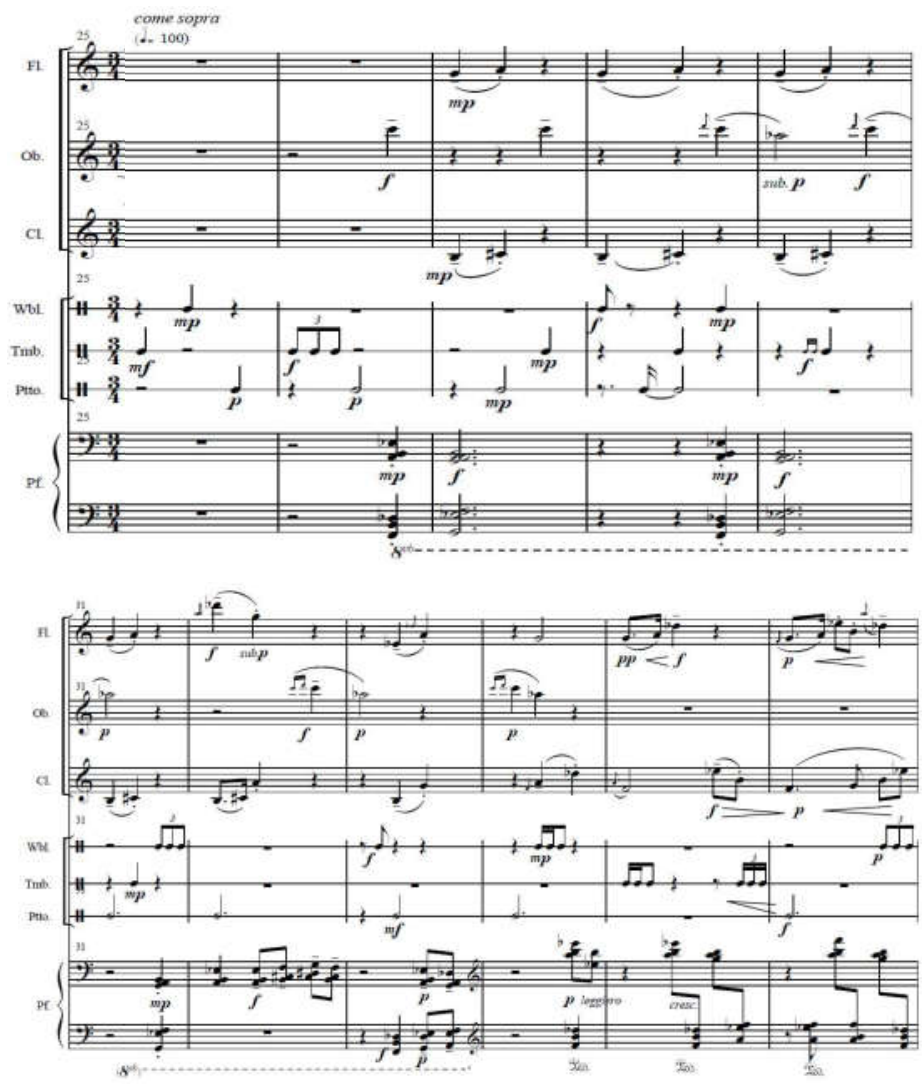

Since the pitch $\mathrm{G}$ in the fourth movement is not only the climax of the upper part of the two-part counterpoint between flute and clarinet $\left(\mathrm{G}^{3} / \mathrm{b} .14-15 /\right)$, but also of all the material presented in the flute part from the beginning of the 
composition till that moment, ${ }^{25}$ it is inevitable to connect it with the process that started in the second movement. But is it justified to think of that pitch as the goal of the aggregate completion process in the melodic layer of the work? Does Zatkalik the composer confirm Zatkalik the theorist's thesis that 'we are almost bound to find aggregates if we search for them on a large scale' and that their analytical significance is reduced under the circumstances, ${ }^{26}$ or does he deny/ reinterpret/redefine it?

Looking from a strictly theoretical point of view, the existence of the two elements doesn't speak in favor of the claim that $\mathrm{G}^{3}$ in bb. 14-15 is significant as the missing last pitch of the aggregate. The span between the second movement, in which the exhaustion of the family of entities in the melodic layer was in fact disabled by the absence of $\mathrm{G}$, and the fourth movement, where the occurrence of that pitch is so prominent, is indeed broad enough to make the analytical views on the aggregate completion 'strained' to a certain extent. Except for that, $G$ has already occurred quite "inconspicuously" in b. 4 of the fourth movement in the clarinet part, which means that it doesn't represent an analytically relevant event for the examination of the structural meaning of the aggregate completion in the musical work. ${ }^{27}$ However, from a strictly musical point of view, there is something very conspicuous in that 'inconspicuousness' of the pitch G in b. 4: not only that it fulfilled neither its closural nor non-closural, dramatic/expressive or idiosyncratic function of the aggregate in that bar, ${ }^{28}$ but it was, above all, meant to be played in ppp dynamics and imperceptibly. All of this enabled the repetition of the pitch $\mathrm{G}$ to achieve significance in the global sense, for from that point onward the musical flow can continue with some other agenda in mind.

And that is exactly what happens. The described reaching of the last tone of $\mathrm{WS}_{2}$ in the melodic layer is a part of a process of the exhaustion of the chromatic scale pitch fund: ten pitches of the chromatic total were used in the two-part counterpoint from the beginning of the fourth movement till the end of the $a$ section. The pitches $\mathrm{B}$ and $\mathrm{A}$ are missing from the process of aggregate completion. And

25 The $\mathrm{G}^{3}$ is followed by the lower climax in the lower part of the two-part counterpoint (D /bb. 15-16), at the same time the lowest pitch of the clarinet part from the beginning of the composition till that moment. The $\mathrm{D}-\mathrm{G}^{3}$ interval can be understood as a particular 'tonic' in regard to the beginning of the fourth movement (F-sharp $\left.-\mathrm{C}^{2}-\mathrm{D}^{3}\right)$. If we accept this tonal hint, then the last chord of the third movement $\left(\mathrm{E}-\mathrm{C}\right.$-sharp $\left.{ }^{2}-\mathrm{C}^{3}\right)$ gets the function of the subdominant of that progression, which indicates the 'traditionally' conceived strategies of the goal-oriented musical process.

26 Miloš Zatkalik, “The Aggregate...”, op. cit., 81 (note 19).

27 Cf. ibid., 80-81.

28 The classification of the functions of the aggregate is given in: ibid., 75-80. 
these are the very pitches that - after an extensive prefix in the flute and the clarinet parts (bb. 22-31), above the piano accompaniment similar to the one from the $a$ section - the melodic line of the $b$ section begins with, marcato and espressivo. This completion, unlike the previous one, is conspicuous and has an emphasized dramatic/expressive function. The key pitches are entrusted to the English horn, not by accident: it is a register variant of the oboe which was 'displaced' from the major flow of events in the second movement and, except in the initial three-tone vertical, did not participate in the fourth movement's first section.

Thus, the chromatic scale gets its tonus finalis (A) which establishes itself as the pitch center of the fourth movement's $b$ section: the tritone G-sharp-D in the English horn part (bb. 33-37) and the establishing of the pedal tone A in the lowest register of piano (from b. 34) speak in favor of this claim. ${ }^{29}$ (Example 3)

Example 3: Miloš Zatkalik, Noise in Inner silence, 4th movement, bb. 31-37.
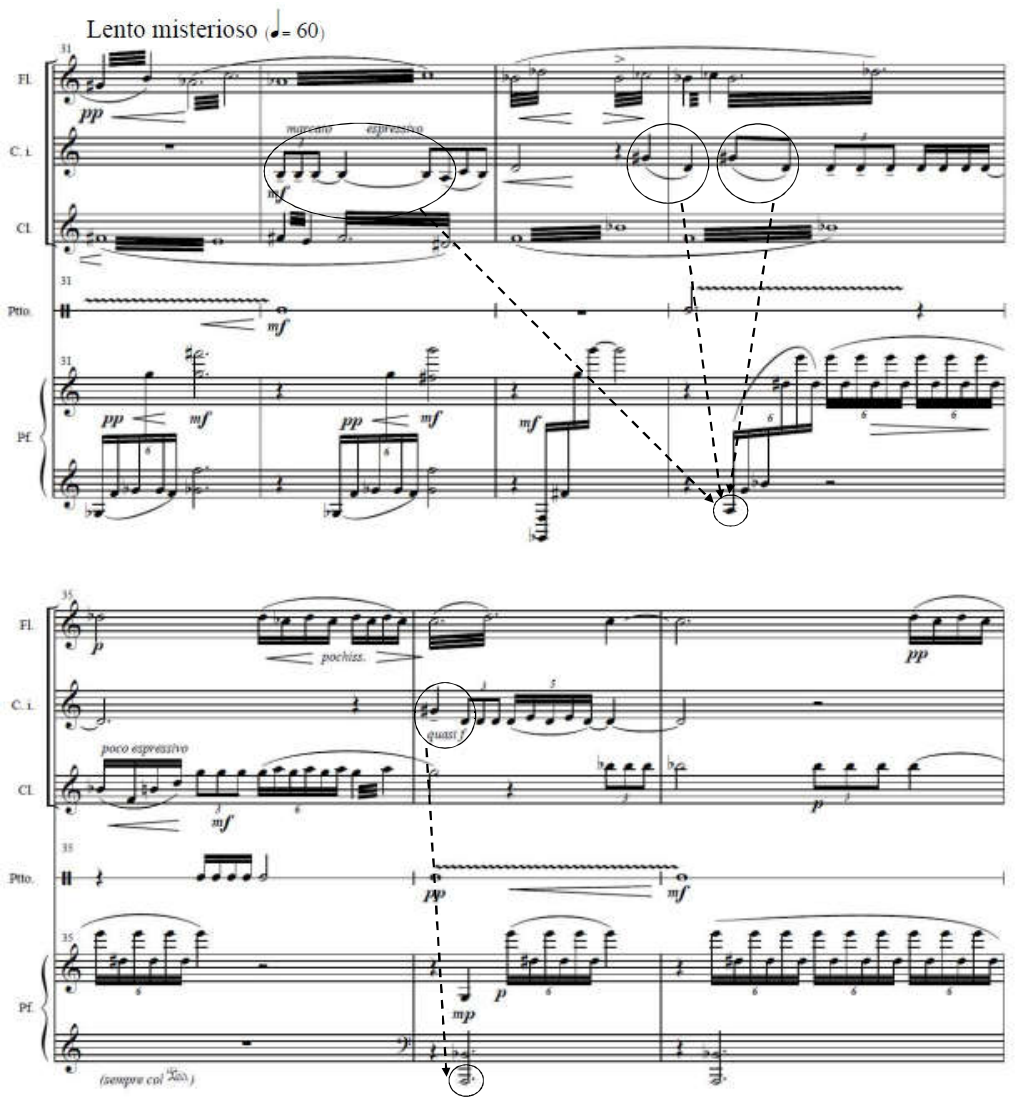

29 The piano accompaniment is based on the $\mathrm{OS}_{1}$ subsets in this segment. 
However, alongside with this affirmation, there is also a metamorphosis of the melodic layer's scale basis, from the chromatic to the whole tone one $\left(\mathrm{WS}_{1}\right)$ that is implicated by the tritone G-sharp - D. In addition, the primarily melodic character of the English horn part becomes the role model for the change of the function of the other two wind instruments: from the melodic line accompaniment to the equal participation in the three-part texture. In its melodic fragments echoes the second movement's first section. Thus, far from the "obsession with forcing into the composition some semi-clandestine signals which purported to contribute to its coherence and integration", close to the utterly refined music logic and the subtle composer's gesture, the equivalent relationship is established between the fourth and the second movement.

Consequently, pitch A is not 'just' the "point of arrival" that one of the streams in the fourth movement was tending to, but the whole $b$ section also represents a certain "state of affairs" by which the relations within the overall plan of the work are established, with a certain dose of nostalgia, one could say. Not only is the equivalence with the second movement incomplete, but - like a memory of the events that cannot be repeated as such - it is 'softened' in several ways: the accompaniment on which the melodic phrases are generated is not indifferent anymore, but "easy and delicate" (sempre leggiero e delicato /from b. 27/); the groups of tones with the melodic meaning are not given in forte dynamics here, but they are dynamically individualized and tinted; the motivic work and the liquidation of the material do not lead to the sound climax, but, quite the opposite, to the tranquilization of the musical flow.

Hence, the conception of the fourth movement's Coda (bb. 40-56) leads to the literal disappearance of sound. Although A still functions as the pedal tone and there still is the whole tone scale basis of the music material exposed in the wind instruments, that material does not implicate $\mathrm{A}$ as its pitch center. On the contrary, these parts are based on such a textural hierarchy that the characteristic rhythm (the inverted syncopation) and the individualized articulation (frullato) of the flute part provide the leading position to the tone $\mathrm{C}^{1}$ compared to the ostinato repetition of the pairs of tones in the English horn (A-flat - B-flat) and the clarinet parts $(\mathrm{E}-\mathrm{D})$. The fact that the piano part chordal accompaniment in this segment is based on the sets [0134] and [014] - whereby the first one is the complement of the second and therefore closely connected with it - indicates that the pitch $\mathrm{C}$ is not emphasized accidentally. Therefore it seems that the initial rhythmic pedal (bb. 40-43) and later the pedal on the sustained ${ }_{2} \mathrm{~A}$ (bb. 50-55) belong to an entirely different dimension of musical events. The peculiarity of A in the given context is additionally stressed by the use of alternative ways of performing (by pressing and scratching wires). 
It is necessary to summarize our observations so far, before we further explore the meaning of the pitch A: (1) both the 'whole tone' and 'chromatic families of entities' were transformed from the vertical to the horizontal dimension; (2) they are both exhausted at a distance, whereby the completion of the 'whole tone family' is achieved within the unfolding of the entity of the chromatic one and the exhaustion of the 'chromatic family' redirected the musical flow to the whole tone context; (3) the pitch A, as the initial pitch center of that context, is put aside because $\mathrm{C}$ is affirmed as the pitch center and it is followed by 'its' pitch fund. To unloose the Gordian knot of the expectations and goals already achieved - but to a certain extent defamiliarized - three things are left: the transformation of the 'octatonic family of entities' from the predominantly vertical to the horizontal dimension, the resolution of the whole tone 'dissonance at a distance' and the clarification of the relationship between the referential sonority and the tone cluster ${ }_{2} \mathrm{~A}-{ }_{1} \mathrm{E}$ along with the corresponding relationship between the pitch centers $\mathrm{C}$ and $\mathrm{A}$. The first two of the three expected goals will be achieved in the penultimate movement.

The tonal basis of the fifth movement (Molto presto furioso) could be understood in a twofold way. The initial piano part ostinato is based on the set [0268], the superset of the firstly achieved whole tone vertical in the composition, and it includes the tones of the $\mathrm{WS}_{1}$. The chord-like material based on the $\mathrm{OS}_{1}$ is presented above the lower part of the previous material, already in b. 3 . The tones of the lower part of the ostinato are selected in such a way that they represent the subset of the same scale. The gradual 'conquering' of the octatonic scale's horizontal aspect will unfold throughout the $a$ section (bb. 1-21) in the three wind parts. That process carries another - far from a "forced" one - establishing of equivalencies between the movements: the principle that directed the mutual differentiation of the melodic and the 'harmonic' layer of the second movement is recognized in the individualization of the melodic pairs of pitches above the pulsating eighth note triplets background.

When the octatonic scale is finally 'transformed' into the horizontal dimension, a complex developmental, imitative three-stage process commences (bb. 21-66). The exhaustion of the 'octatonic family of musical entities' achieves its clear structural significance with the appearance of the theme, based on a semiquaver rhythmic pulse, created out of all eight pitches of the $\mathrm{OS}_{1}$ at the very beginning of the mentioned process. The fact that the similar theme appears twice more, at the beginning of the second and the third developmental stage (bb. 38 and 55 with upbeat) does not diminish the importance of the completion. On the contrary. It strengthens it by the bare fact that this is the only developmentally conceived segment in the whole work. 
Not only the material of the fifth movement but also the major materials of the whole cycle are subjected to the development. Thus, in the unfolding of the simultaneous ostinato lines based on different rhythmic patterns (bb. 24-36 and 43-48) a quasi-mechanistic character of the initial ostinato develops and stratifies into woodwinds. There is also a simultaneous echoing of the indifferente accompanying textural layer of the second movement within that process. Then, in the first developmental stage the three ostinato lines are accompanied by the pairs of piano dyads (bb. 27-33) which are - without exception - built on one of the combinations of minor ninth and major seventh, similarly to the beginning of the composition. However, they do not represent the chromatic scale subsets anymore, but the octatonic scale ones. The entire pitch fund of that fragment includes all eight pitches of the $\mathrm{OS}_{1}$. Also, in the motivic work in the flute and clarinet melodic phrases and in the subsequent liquidation of the material as well as in the simultaneous 'indifference' of the oboe to its surroundings at the end of the second developmental stage (bb. 49-54), one can notice the procedure similar to the one that led to the first climax in the second movement and it refers to the conception of the fourth movement's section $b$ as well. The triads that accompany this process are based solely on the set [026], the same one that the process of transformation of the three-tone verticals ended with in the first movement. Over and above, it is relevant to remind of the dynamism that the chord conceived out of the seven tones of the $\mathrm{OS}_{1}$ introduced into the developmental process, the chord with the F-sharp as the fundamental tone, the most unstable in relation to the referential sonority.

There is one detail in the thus conceived developmental segment that requires special attention. In the golden section area of the fifth movement (b. 34), in the ending bars of the first developmental stage, between the two ostinato lines in the flute and clarinet parts, literally out of nowhere the C - E-flat - G broken chord appears in the oboe part. This sudden appearance, in no way encouraged by the musical motion, of the consonant tonic's broken chord - not the tonic constituted contextually, but a 'real' one - represents the ironic departure from the complex, multilayered and mutually pervaded goal-oriented musical processes which act on so many levels in this work.

The intensified and substantially altered recapitulation of the fifth movement (bb. 67-90) brings the long-awaited events. In the process of liquidation of the thematic material, the symmetrical subsets of $\mathrm{OS}_{1}$ [0167] and of $\mathrm{WS}_{1}$ and $\mathrm{WS}_{2}$ [0268] - presented in the oboe, flute and clarinet parts respectively and arranged in their real sounding in such a way that the two latter parts form $\mathrm{OS}_{1}$ - finally flow into the referential sonority at the very end of the fifth movement. (Example 4) A similar process unfolds in the piano as well, although in the vertical dimension, where the supersets of the referential ([0134] and [0146]) and 
of the initial whole tone sonority [0268] alternate until the dissonant sonority [0134679] is reached, marked fff possibile, which is the dynamic peak of the piano part in this movement (bb. 78 with upbeat-79).

Example 4: Miloš Zatkalik, Noise in Inner Silence, $5^{\text {th }}$ movement - Pitch fund of the wind parts in the recapitulation (bb. 67-89)

Fl.

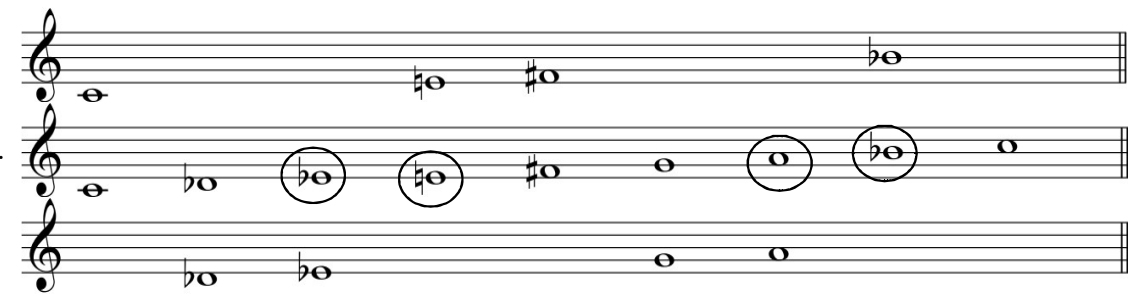

b. 67

F1.

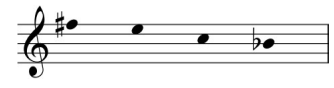

$\mathrm{Ob}$.

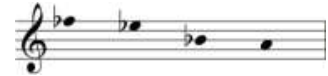

$\mathrm{Cl}$.

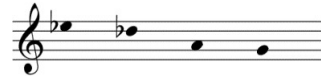

b. 74
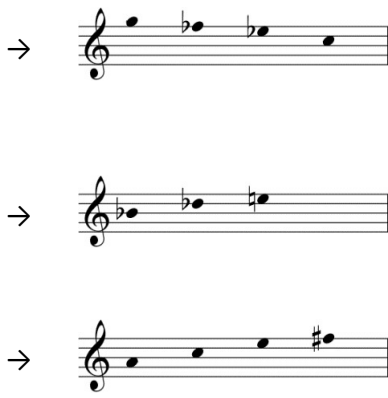

b. $82-83$

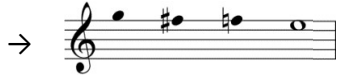

b. $78-83$

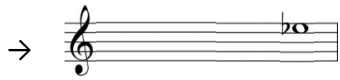

b. $81-83$

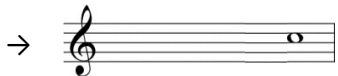

The equivalence between this "point of arrival" and the beginning of the composition is incomplete: there are rhythmical and metrical changes in the woodwind parts which are organized in such a way that the simultaneous sounding of all three pitches is achieved in three gradual steps, their dynamics is varied and the piano part is missing. Therefore, the return to the referential sonority and three-tone verticals in general does not represent the return to the "state of affairs" which the composition departed from. The question is: is that return possible at all after the previous climax?

The noticeable absence of the chromatic scale from the fifth movement is crucial for answering this question. For, the material based on the chromatic scale is the only one that hasn't been oriented to the pitch center C so far. The multiple attempts to confirm $\mathrm{C}$ as the finalis of the composition - by the motion D-flat - C within a predominantly horizontal setting of the chromatic scale in the lowest register - remain futile in the epilogue. Therefore, when 'the rest around 
music is silence', what stays 'in' the music is 'only' A - E: barely audible, chromatically 'blurred', distant and utterly peculiar.

With the last sentence I have stepped out of the integral system of the theoretical assumptions and corresponding analytical strategies into the open and potentially endless space of poetic-narrative-dramatic-visual references of the work. I have opened the door behind which there is a whole new world that although attached to this composition after its creation - waits to be revealed. Therefore I shall, just as the composer has done, end my work with a short epilogue.

When I said in the introduction that my aim is to shed light on the unity of Zatkalik's thinking about and in music, I unintentionally scratched upon the surface of a tenuous and remarkably complex universe of everything that makes his - and only his - "inner silence". My observation in this paper about that vastness was predominantly based on a quite - as it is often considered in music science - objective perspective: the theoretical-analytical one. Although that kind of perspective enabled a thrilling adventure, I have shed light only on one register in which the composition Noise in Inner Silence continued its life in my musical experience. In other words, although I gave to that work one more voice with which it will continue to communicate with its audience, in this rather long text I said quite a few things from another, not completely different, perspective that could have also taken me toward an adventure, an even more uncertain one, it seems. That is why I hereby schedule one more encounter with the composition Noise in Inner Silence, this time a hermeneutical one.

\section{Works cited}

Adorno, Theodor W.: "On the Problem of Musical Analysis. Introduced and translated by Max Paddison”, Music Analysis, Vol. 1, 2, 1982, 169-187.

Despić, Dejan: Harmonija sa harmonskom analizom III. Beograd: Udruženje kompozitora Srbije i Savez udruženja kompozitora Jugoslavije, 1994.

Milena Medić: "Music is not a Language", Interview with Miloš Zatkalik, New Sound, 42, II/2013, 5-16.

Zatkalik, Miloš: “The Aggregate or Have the Notes Lost Orientation?”, Musicological Annual, Vol. XLIV, 2, 2008, 73-74.

---: "Reconsidering Teleological Aspects of Non-Tonal Music", in: Denis Collins (Ed.), Music Theory and Its Methods: Structures, Challenges, Directions. Frankfurt am Main: Peter Lang Publishers, 2013, 265-300.

---: "Teleological Strategies of Nontonal Music: The Case of Milan Mihajlović", New Sound, 45, I/2015, 119-138. 


\section{Summary}

The composition Noise in Inner Silence by Miloš Zatkalik can be understood as a creative transposition of the author's research in the field of music theory during the last ten years or so. As such, it embodies the transformation which - considering compositional technique, musical language and musical expression in general - took place within his oeuvre under the influence of his theoretical work.

One theoretical issue is particularly important for understanding this connection: the one which concerns goal-oriented large scale processes. In the overall spiral dramaturgical flow of the piece both basic strategies - which, according to Zatkalik, enable music to move toward a certain goal - operate: the establishing of the referential sonority and the exhaustion of the family of musical entities. The strategies of projecting and realization of long-term goals in this piece are based on a particular use of and mutual interrelations between two groups of elements: three characteristic scales (octatonic, whole tone and chromatic) along with their contextually implied pitch centers ( $\mathrm{C}$ and $\mathrm{A})$, on the one hand, and textural, on the other.

The referential sonority is established as a subset of the octatonic scale. The departures from the referential sonority are realized in the joint action of three elements: its relatedness with other tone structures, the interval of the transposition of the given sonorities and the transpositions of the scale itself. Through the globally constituted relation stable-unstable-stable there operates one more process which is also of key importance for the overall structure: the exhaustion of the pitch fund of the three mentioned scales and their 'transition' from the predominantly vertical to the horizontal dimension. Consequently, there is a musical entity based on one pitch class which becomes the constituent of the three mutually related families of entities (the first transposition of the octatonic scale starting from $\mathrm{C}$, the chromatic scale and the two transpositions of the whole tone scale), on the one hand, and a musical entity based on a type of texture that becomes a part of a two-member constellation of a vertical and a horizontal dimension of the musical flow, on the other. These processes run one after another, mutually interweave and entangle in a specific way in the area around the golden section of the composition. The first point of their disentanglement is realized in the intensified recapitulation of the fifth movement, while the second one is given in the epilogue. 